\title{
Identifying the Main Service Elements for Customer-Oriented Live Guided Virtual Tours
}

\author{
Rosa Repo and Juho Pesonen ${ }^{(\bowtie)}$ \\ University of Eastern Finland, Joensuu, Finland \\ juho.pesonen@uef.fi
}

\begin{abstract}
Virtual tourism allows people to see and experience the world without physically travelling to the destination. The objective of this study is to identify service elements critical to the development of customer-oriented live guided virtual tours. A total of three focus group discussions were conducted, with 4-5 participants in each group. All the participants were Japanese who had previously participated in live guided virtual tours. The data was analysed with qualitative content analysis, where an inductive approach was used. The findings reveal that the main expectations of the participants are related to experiencing the local culture and way of life, feeling of actually being in the destination (sense of connection), social interaction and active participation. These factors make the virtual tour feel realistic and attractive and the tourism businesses need especially to focus on these when designing virtual tours for example by providing ample opportunities for the virtual tour participants to discuss with each other and learn from each other. This study brings valuable insights into the virtual tours research from the customer perspective, especially in a nonWestern context.
\end{abstract}

Keywords: Tourist experience $\cdot$ Virtual reality $\cdot$ Guided tour $\cdot$ Experience design $\cdot$ Content analysis $\cdot$ Virtual tourism

\section{Introduction}

Virtual tourism allows people to see and experience the world without physically travelling to the destination. So far virtual reality in tourism is mostly explored from a marketing perspective [1]. However, research has begun to focus on guided virtual tours during the COVID-19 pandemic [2]. When COVID-19 halted the traditional inperson visits, many attractions, sites, destinations and businesses started to invest in virtual tours [2]. Virtual tourism also can help to promote sustainable tourism and enhance virtual accessibility [3]. However, within the virtual tourism field, there have not been studies on a relative novel phenomenon of live guided virtual tours. These tours are similar to other tours in tourism but they happen completely online. They are completely or partly recorded and there is always a live guide on the tour. For example, during the pandemic many Airbnb Experiences hosts had to transform their destination tours into live guided online tours. Even though Airbnb Experiences have been studied in the tourism literature [4], the online live versions of these tours have not received

(C) The Author(s) 2022 
considerable attention. These live virtual tours can be considered as tourism experiences in themselves. As the phenomenon is still relatively new, there is a lack of research on what kind of experiences live guided virtual tours are and why tourists join these tours.

Customer perspective is critical in designing successful virtual tours [5]. Virtual tourism experiences have to be able to offer a satisfying user experience, not only from the technological perspective but also from the content perspective [6]. The goal of this study is to identify what are the main service elements of customer-oriented virtual tours. We test the usefulness of the customer-oriented tourism service model [7] in the context of virtual tours and aim to identify the critical elements of the service concept, process, and system. We also contribute to virtual tourism research by studying Japanese virtual tourists, which is a culture and a market that is often overlooked in research [8].

This study is done as a part of a tourism development project called Experience Kalevala which aims to design authentic travel experiences by combining Finnish nature, culture, and stories of Kalevala, the Finnish national epic [9]. One goal of the project is to develop a virtual tourism experience, a live guided virtual tour, that utilizes all the factors just mentioned. The target group of the pilot project are Japanese customers, and thus Japanese customers are also the target group of this specific study more precisely Japanese customers that have already participated in a virtual tour, so they already have an idea about virtual tourism experiences. There have been calls for more research in a non-European context [8] on virtual tourism. This study provides more insights into the Japanese market by exploring their expectations and discusses how this understanding can be used in new service development.

\section{Theoretical Framework}

\subsection{Virtual Tourism and Virtual Tours}

Virtual tourism has gained considerable attention during the COVID-19 pandemic. Virtual tourism can be considered to include virtual reality (VR) and augmented reality (AR) applications as well as live broadcasting and streaming of tourism [3]. Virtual tours can be considered as a specific type of virtual tourism.

The term virtual tour is widely used on tourism organization websites, even though there is no clear consensus about the term. Virtual tours are said to be presentations of existing (or previously existing) locations, often consisting of a series of videos and photos [2]. They can also include other multimedia elements like sounds, speech, music, and text. Virtual tours can be distinguished from the programs presented on television as they are more interactive. Virtual tours often allow people to explore the environment in a similar way they could do in real life, but it only happens through computers and the exploration of space is limited only to points that are defined in advance [10]. In other words, there is no possibility for completely free navigation [11]. Virtual tours are also said to be a specific type of virtual experience that include computer-mediated interaction when exploring a destination [10]. During the COVID- 
19 pandemic, many museums and cultural heritage sites have launched virtual tours using virtual reality technologies [2].

Virtual tours and tourism are now being intensively studied in the academic literature. El-Said and Aziz [2] studied what affects a person's decision to go on virtual tours. They found out that the Technology Acceptance Model and Protective Action Decisions Model can be integrated to effectively predict users intention to adopt virtual tours and that virtual tours increase the tendency to visit the actual tourism site. Lu et al. [3] used a mixed-methods approach to study the factors influencing the use of virtual tourism. They found out that among the Chinese tourists in their study, virtual tours in museums and other indoor sites were the most popular and that tourists are willing to use virtual tourism after the pandemic is over. Kim et al. [12] used a stimulusorganism-response theory to understand what factors make consumers visit the destinations they visit in VR. They identified authentic experience as an important factor in VR tourism and that cognitive response influenced intention to visit a destination in VR more than affective response. In a recent literature review, Wei [8] identified instrumental, experiential, psychological and social dimensions as aspects that users refer to when they describe and evaluate their virtual tourism experiences.

All the different types of virtual tours and videos of destinations have so far been mostly free to access for the consumers because they have been used as tools for promoting the destinations or tourism products. However, virtual tours that customers are paying for is a new phenomenon raising from the COVID-19 pandemic [13]. As customers have not been able to physically travel, they are replacing their physical holidays with virtual experiences. Tourism companies are offering so-called live virtual tours, guided virtual tours, live online tours, digital tours and live online experiences and customers are indeed paying for these experiences. The live connection is a new development step on virtual tours. There is a live guide who can interact with the participants online. In many ways, these guided virtual tours resemble traditional tours but utilize ICTs to connect the guest, the guide (host), and the destination in virtual form. Research on Airbnb Experiences tours has shown that user characteristics and tour guiding service are the most relevant factors for tourist satisfaction with tour and service [4]. However, little information is still available on what are the important characteristics of guided virtual tours from the customer perspective. For example, Wei [8] did not identify any papers related to the topic in the recent literature review between 2000-2018. Thus this is a relatively novel and underresearched field at this moment.

\subsection{Modelling Tourism Services}

Live guided virtual tours can be considered as tourism services. To be able to provide services for tourists, businesses need to understand their service concept, service process, and service system [7]. The service concept relates to the needs of the customers, and it explains how these needs can be fulfilled with the design of the service package or the content of the service [14]. Service process means a series of sequencing functions that should operate accurately so that the company can provide the service. By focusing on the important functions, the correct quality at a rational price can be achieved [14]. The last component, the service system, relates to the resources that are 
available for the service process [7], for making the service concept possible through the processes that utilize these resources. The resources might include for example the staff, physical and technical environment, customers, and organization [14].

The service concept is at the core of everything. The service concept refers to the idea of the value that customers desire [15]. In other words, it is the answer to the customer's expected value [16]. For this reason, the empirical research in this paper aims to find out what the customers expect of the live guided virtual tours so that the service concept for the Experience Kalevala online experience can be developed. The service concept is enabled by the service process. For the customer, it means the visible components of the service, expressed for example in the form of a brochure, while for the company it means the chain of activities that can be presented for example with blueprints [15]. The service system for tourism products includes internal and external resources, hospitality, image and business mission. Together these three mentioned components create the prerequisites for tourism experiences [1].

Defining the tourism service model is an important step in the service development process. Understanding the service from the customer perspective enables novel service concept design [17]. Thus, this study aims to identify service elements at the concept, process, and system levels from the customer perspective for live virtual guided tours.

\section{Research}

\subsection{Target Group and Data Collection}

The research approach for this study is the qualitative approach. The qualitative research approach is used when the studied phenomenon requires holistic understanding [18]. The qualitative approach was chosen for this study as the purpose of this study is to understand the expectations toward live guided virtual tours from the perspective of Japanese customers, and develop a new service based on their expectations and perceptions.

In this study, the data was collected through focus group discussions. Focus group discussion refers to a data collection method where a group of people is "focused" on discussing a specific topic or issue [18, pp. 181]. Focus groups are commonly used in academic marketing research to study consumer behaviour, including customers' attitudes, needs, perceptions, preferences and choices [18], as well as opinions, values, expectations and perspectives [19], and therefore it works well as a data collection method in this empirical study. Eriksson and Kovalainen [18] state that focus groups can be used in three ways; as an only method, when the focus groups are the only source for empirical data, as a part of multi-method qualitative research, or as a supplement to a survey. In this study, the focus groups were the only data collection method.

The purpose of this study was to recruit Japanese people who had previously participated in a live guided virtual tour. For this reason, the researchers contacted a person who was familiar with this target group - a virtual tour guide from Japan. The participants for group discussions were recruited through her networks, as Eriksson and Kovalainen [18] state that participants can be recruited for example through a contact 
person who knows the target group well. A total of 15 people enrolled on the study, but one of them had to cancel at the last minute. In the end, three group discussion sessions were conducted. In two of those groups, there were five people, while in one group there were four people. The group discussion sessions were organized online, using the Zoom platform during Spring 2021, as the COVID-19 situation prevented physical meetings. Two facilitators were present in the Zoom meetings, one focusing on taking notes and the other keeping the conversation ongoing.

The participants were asked some background questions in a separate form (Table 1). All the participants of the group discussions were females, so unfortunately no male perspective on the matter was included in the study. The positive factors were that the age range, as well as the number of virtual tours taken, had a wide range. Participants' age ranged from 26 to 61 . The number of times participants had taken a live guided virtual tour ranged from one to even 30 . The participants were asked if they were interested in participating live guided virtual tour again and if they were interested in participating in a virtual tour also after the pandemic when there are no more travel restrictions. Everyone answered both of these questions with "yes". They were also asked if they would consider replacing a holiday trip with virtual tours, and 12 out of 14 answered "yes" to this as well.

For this study, a group discussion guide with semi-structured questions was created $[18,19]$. The questions focused on their previous experiences in live guided virtual tours and what kind of expectations and desires they had towards live guided virtual tours. The questions were designed to identify the prerequisites for customer-oriented tourism products and services [7]. The questions focused on the previous experiences of the participants as well as on the expectations and desires.

\section{Previous Experiences}

1. For what reasons did you decide to take part in a guided live virtual tour in the first place?

2. How would you describe the experience?

- What was particularly memorable and meaningful?

- Is there anything you would have changed or added to the experience?

3. Compared to traditional travelling, what kind of benefits virtual travelling has brought you?

\section{Expectations and Desires}

4. Please describe your general expectations for guided live virtual tours.

- Next time you decide to purchase a virtual tour, what do you especially expect from the experience?

- What are the most important factors for you?

5. What kind of content in the virtual tours would be most desired or most attractive for you? 
6. After showing some photos and videos of Finnish nature and Kalevala: What would you want to particularly experience in a virtual tour that is combining the elements of Finnish nature, culture, and Kalevala?

Before the last question, some photos and videos were shown to the participants to give them an idea of Kalevala. Other materials or special techniques were not included as they would have been complicated (or at least too time consuming) to arrange through Zoom. Due to the time limitations of the participants, one hour was reserved for each group in this research, and this was told to the participants in advance. It was enough to go through all topics in the group discussion guide, as the facilitator made sure that all the topics were discussed during the sessions. All the sessions were videorecorded and transcribed, including all the non-verbal notions.

Table 1. Focus group discussion participant information.

\begin{tabular}{l|l|l|l|l}
\hline Group & Participant & Age & Occupation & $\begin{array}{l}\text { Number of live guided virtual } \\
\text { tours taken }\end{array}$ \\
\hline \multirow{2}{*}{ G1 } & P1 & 40 & Freelancer & 1 \\
\cline { 2 - 5 } & P2 & 49 & School assistant & 7 \\
\cline { 2 - 5 } & P3 & 45 & $\begin{array}{l}\text { Freelancer, interior } \\
\text { coordinator }\end{array}$ & 5 \\
\cline { 2 - 5 } & P4 & 51 & Consultant & 10 \\
\cline { 2 - 5 } & P5 & 56 & $\begin{array}{l}\text { Construction company } \\
\text { worker }\end{array}$ & 1 \\
\hline G2 & P6 & 60 & High school teacher & 8 \\
\cline { 2 - 5 } & P7 & 30 & Part-time worker & 5 \\
\cline { 2 - 5 } & P8 & 45 & English teacher & 3 \\
\cline { 2 - 5 } & P9 & 28 & Web editor & 4 \\
\hline \multirow{5}{*}{ G3 } & P10 & 56 & $\begin{array}{l}\text { Interior coordinator \& } \\
\text { life coach }\end{array}$ & 2 \\
\cline { 2 - 5 } & P11 & 35 & Travel agent & 30 \\
\cline { 2 - 5 } & P12 & 61 & Architect & 15 \\
\cline { 2 - 5 } & P13 & 50 & Teacher & 2 \\
\cline { 2 - 5 } & P14 & 26 & Local official & \\
\hline
\end{tabular}

\subsection{Data Analysis}

The data were analysed through qualitative content analysis, as it is often used for drawing together and comparing focus group data, and it aims to provide a holistic picture of the studied subject [18]. Content analysis is a flexible method of analysing written, verbal, or visual data, and it is used for systematically describing phenomena [20]. It can be used in both qualitative and quantitative studies, and in an inductive and deductive way. The purpose of the study determines the used approach. The inductive way is recommended to use if there is not enough previous information about the phenomenon, whereas the deductive approach is used when the structure of the analysis 
is based on previous knowledge and the purpose of the study is theory-testing [20]. In qualitative content analysis, the coding categories are commonly derived inductively from the data, meaning that the coding scheme is generated with the help of data, and this allows the creation of new theoretical and conceptual ideas [18]. Therefore, an inductive approach was used for analysing the data in this study. The inductive approach is also described as a conventional approach [21].

First, all the group discussion sessions were transcribed. This included also all the non-verbal notions that the researcher made, e.g., body language, emotions, and nonverbal agreements and disagreements. The data analysis started with reading through the transcripts several times and getting familiar with the data. This was done to achieve a sense of the whole data set [20,21]. The familiarizing is referred to as the preparation phase, after which comes the organizing and reporting phases [20]. Once the researchers were familiar with the data, it was time to move on to the next phase. The organization stage started by going through the text again and underlining phrases, sentences or expressions that were relevant to the study. This is also known as coding $[18,20,21]$, and it was done manually on a Word document.

The researchers first underlined those statements that were either common or exceptional. From the focus group data, it would be important to analyse issues that are repeated by several participants or by several groups, and on the other hand issues that are disagreed by several people or discussed by only one group [18]. Attention was paid especially to the commonly repeated issues, different issues between the groups, and to the situations where someone brought out an issue, and then others in the group demonstrated agreement verbally or non-verbally [18]. The coding was done by one of the authors and random checks were performed by the other to ensure an agreement that the coding was done correctly. Once the whole data set was coded, the codes were collected on a separate Excel sheet and then grouped to create categories. First categories were created around similar topics, and these topics were then categorized according to the service system model. In the last phase, the created categories were again grouped to create bigger main categories. This is known as abstraction [20].

\section{Findings}

As the goal of this study was to map out the main service elements for guided virtual tours, we focused on the customer perspective of the service concept, service processes, and service system. The context of the research is the Kalevala themed virtual tour. The main findings of the study are presented below, and all the data from the interviews were used to create Fig. 1 as a comprehensive demonstration of the results.

\subsection{Service Concept}

The service concept of live guided virtual tours can be constructed around the realistic feeling of actually being there, interaction with other people, experiencing local culture and way of life, and active participation.

The realistic feeling was strongly connected to the other memorable and meaningful factors. 
"It was good that there were local people included to the tour, as it made the tour more realistic. I actually never thought the virtual tour would feel so real, so I was quite surprised that I would feel like we were actually travelling there, and like we were actually meeting those people." (P8)

Interaction with other people was also a widely discussed factor in all groups. With this the participants were either referring to interaction with the other participants of the live guided virtual tour, as it was stated that "having small group discussion with other participants was memorable" (P6) and "I was very impressed, and it felt memorable, to have the group talks" (P11), or with the local people involved in the tour, as it was stated that "I was also able to talk to the local people directly, which was very exciting for me" (P1).

Those who were referring to the interaction with local people, also felt that experiencing local culture and way of life is a meaningful factor in the tours. They were referring especially to local people's lives and learning about them by meeting locals. For example, P1 was mentioning the interaction (discussion) with local people, but she also said:

"I would say that being able to experience the lives of local people was most memorable. It was interesting to see and visit a local home, as we visited Danish architect's private home, and learned about his life."

Active participation (through live connection) was also a highly expected attribute of live guided virtual tours. The participants were stating that they do not want to just watch and listen, they want to be involved somehow themselves, and actively participate in the tour. This is possible through the live connection, as the participant can discuss, ask questions, and participate in activities in real-time. It is similar to Cho et al. [22] stating that on web-based virtual tours it is important to make customers active participants, "players", instead of passive participants, "watchers". These findings prove that this is also expected from the customers' side. Participants stated for example the following:

"I expect the guide to involve everyone on the tour, and not just to talk about the places like keeping some kind of presentation." (P9)

"What I want is an interactive experience, rather than a one-sided reception like watching a TV. I want to feel like I am actively participating the tour." (P4)

"This was mentioned before, but having short surveys or quizzes makes us feel like we are actually participating the tour. Because if we are only looking at the photos and videos, or listening to the speakers, it would not really feel like we are on a tour." (P8)

These four elements seem to form the service concept of live guided virtual tours. They differentiate live guided virtual tours from other virtual tourism experiences and especially from online museum tours that have become commonplace. This contributes to the literature by identifying the unique value proposition as the reason to use virtual tour services. Whereas previous studies have used the Technology Acceptance Model [2] or Theory of Planned Behavior [3] to explain the use of virtual tourism, we suggest that understanding customer perceptions of expected value is a useful approach. 


\subsection{Service Process}

The service process explains how the service concept can be delivered to the customer. Several important elements could be identified from the data.

Videos and images of real places were desired by all participants, so those can be considered as important content to include in the tours. All the participants wanted to watch videos and images while on the virtual tour. The desired content of the videos themselves was varying according to the participant, but all of them wanted to see videos from the real environment, such as nature, buildings, attractions, and so on. Videos of nature sceneries were most often mentioned: "video clips of nature, for example, going to the woods step by step, as it would feel realistic" (P6). As can be seen from that example, the videos often make the tour feel more realistic, as if the customers would be there. In the discussions, there was no mention about the types of videos and no preferences for example for 360-degree videos. However, this might be because they had not seen these types of videos on their previous virtual tours.

Meet and greet with local people was also often expressed among the participants because all but one participant mentioned it or agreed about it. For example, the following statements were made: "the kind of content I seek from virtual tours is meeting local people" (P12), "for me, it would be fun to communicate with local people in real-time" (P2), and "I would also want to talk to the locals" (P1). Therefore, it would be crucial to always include local people in the virtual tours, so that the participants can meet and talk to them.

Group discussions refer to the discussions with other participants of the virtual tour. The participants of the tour are usually divided into smaller groups, where they can talk with each other and share their experiences. For example, P11 said that: "It was so much fun to discuss and talk with other people in the group, so I would desire that also from my future virtual tours."

All the participants wanted to hear stories of Kalevala and storytelling during the Kalevala-themed virtual tour, for example: "I am very interested in hearing the Kalevala stories and mythology, and also the background of Kalevala" (P11) and "I want to hear more about Kalevala and how the stories connect to the nature" (P13). However, it was not stated that in which forms the stories should be presented, as the participants just said they want to hear the stories. The stories could be still presented together with videos, images or 3D presentations to make them even more appealing.

Q\&A sessions were again talked about in all groups. Discussions in small groups and with local people seemed not to be enough, as the participants wanted to have time specifically reserved for questions and answers sessions. Besides the local people, they wanted to ask questions also from the guide and the companies included in the tour. As an example, it was stated that "I want to ask questions from them about the place and about the life there" (P2) and "I want to ask many questions, so I also prefer having enough time for asking and answering to these questions" (P11).

Activating tasks (quizzes, surveys) as well as "souvenirs" were discussed only in the G2. However, also these were expressed with unusual importance. For example, P7 said that "the quizzes were so much fun, and made us feel like we are participating, that I would like to have those in the tour". "Souvenir" does not necessarily need to be any physical item, but just some kind of memory from the tour. It was said that "after 
the tour it would be nice to get some kind of "souvenir" or "gift" as a memory from the tour" (P7), "I agree, it would be nice to get something afterwards, even if we would need to add some money to it. I was thinking that for me it would be nice to get even some tasks to do afterwards" (P8).

The service process emphasizes various means of interactivity between the tour guide and the guests. This interactivity can be considered as the main characteristic of the live guided virtual tour service delivery process. Whereas in many other forms of virtual tourism the tours can be launched online and they work independently, live guided virtual tours need the host and preferably other organizers and representatives of local people that utilize storytelling and many digital tools available to increase interaction in real-time.

\subsection{Service System}

The service system enables the service process. In live guided virtual tours the destination characteristics such as local culture, people, businesses and their employees, history and nature and landscapes form a major part of the service system. These factors enable differentiation among live guided virtual tours when, for example, the online platforms used all over the world are similar to each other.

All the participants also expected to see sceneries of Finnish nature (lakes and forests). This was expressed for example as "viewing the lakes and forests" (P5) and "seeing nature and forests" (P14). Finnish culture \& history was desired by almost all participants. One of them stated that "the more we hear about the history, culture and Kalevala stories, the more we can learn from your current culture and life" (P2). All in all, the connection between Kalevala, the Finnish culture and nature seemed to be very interesting for the participants. Related to nature, they also desired to hear some sounds of nature to feel more connected to the place. For example, P14 stated that: "Being in the nature and hearing birds singing, it would be very relaxing. - If I close my eyes and listen to the sounds, I could feel like being there".

\section{Conclusions and Discussion}

This study aimed to identify the main service elements for customer-oriented live guided virtual tours. Figure 1 describes the service system model. At the heart of live guided virtual tours are the experiences of local culture and the way of life, the feeling of actually being in the destination, and social interaction and active participation. The service concept of the live guided virtual tours can be designed around these elements. These differentiate live guided virtual tours from other forms of virtual tourism. The service process should focus on enabling the interaction between the host, the locals, and the guests using online tools such as Q\&A sessions, quizzes and surveys, multimedia, and storytelling.

The service system provides resources for the service process. In live guided virtual tours the local destination, its history and culture, people, businesses and natural surroundings are the key resources. Live guided virtual tours can be designed to be based on these resources as the virtual tourists, especially the Japanese tourists in this study, seem to be people who value these aspects. 


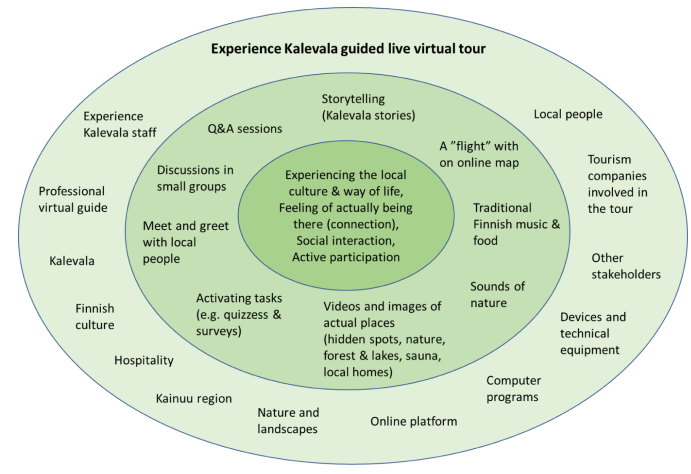

Fig. 1. Prerequisites for Experience Kalevala live guided virtual tour.

Virtual tourism has gained considerable attention during the COVID-19 pandemic [2]. It has been regarded as an alternative business model during the pandemic for many tourism businesses and attractions, it can help promote sustainable tourism, and improve virtual accessibility of tourism services [3]. The results of this study show that live guided virtual tours can indeed even replace actual travel, but this effect was not thoroughly investigated as it was out of the scope of this paper. Many of the respondents had already taken several live guided virtual tours with one respondent (P11) claiming to have participated in around 30 tours. This means that the service provided by these tours is indeed valuable for tourists and loyalty towards this kind of tourism service can be identified. This suggests that there will be demand for live guided virtual tours also after the pandemic.

The findings of this study show that Q\&A sessions, videos of hidden spots and joyful experiences can provide value for customers. Also, storytelling, discussions with other group members, meetings with local people, activating tasks, all types of videos (including real-time videos), sounds, traditional music and recipes, 3D presentations, as well as some "souvenirs" of the tour may provide value for customers. The results demonstrate how important interactivity is in these tours and that this aspect differentiates live guided virtual tours from other forms of virtual tourism.

The factors mentioned above would work for all types of live guided virtual tours. However, customers prefer that virtual tours have some kind of theme or topic, like in the case of Experience Kalevala virtual tour. The expectations regarding Kalevala-themed virtual tour refer to hearing the stories of Kalevala, seeing sceneries of Finnish nature (lakes and forests), hearing nature sounds and traditional music, learning about Finnish history, culture, and traditions, and experiencing Finnish saunas. Nature is a muchdesired element. Hence, the uniqueness of live guided virtual tours comes from the special combination of all of these. It needs "live like a local" experience and a sense of connection to the destination through content from the real environment, while also including discussions and active involvement through real-time connection. Also easy access from home through an internet connection and web-based platforms is needed.

This study contributes to the theory in several ways. First, it is one of the first studies to explore a special type of virtual tour, namely live guided virtual tours. Earlier 
literature on virtual tours has studied mostly pre-made video tours such as museum or heritage site tours [2]. However, the results show that live guided virtual tours have a specific interactivity component that separates them from other types of virtual tours. Second, this study examines Japanese virtual tourists and provides evidence on this often overlooked, non-Western market [8]. Third, this study validates the use of service concept, service process and service system to understand the main elements and building blocks of virtual tourism experience [7].

In conclusion, it can be said that live guided virtual tours provide unique benefits as they allow people to experience the culture and atmosphere of the destination country and other realistic aspects of tourism interactively using technology, without physically visiting the destination. Virtual tourism is thus capable of providing realistic tourism experiences, even though it takes place through technological devices.

\section{References}

1. Karadimitriou C (2020) From real to virtual: nature tourism insights. Int J Spa Wellness 2 (2):65-77. https://doi.org/10.1080/24721735.2020.1770982

2. El-Said O, Aziz H (2021) Virtual tours a means to an end: an analysis of virtual tours' role in tourism recovery post COVID-19. J Travel Res, 0047287521997567

3. Lu J, Xiao X, Xu Z, Wang C, Zhang M, Zhou Y (2021) The potential of virtual tourism in the recovery of tourism industry during the COVID-19 pandemic. Curr. Issues Tour, 1-17

4. Moro S, Rita P, Esmerado J, Oliveira C (2019) Unfolding the drivers for sentiments generated by Airbnb experiences. Int J Cult Tour Hosp Res

5. Edvardsson B, Kristensson P, Magnusson P, Matthing J, Gustafsson A (eds) (2006) Involving customers in new service development. Imperial College Press, London

6. Argyriou L, Economou D, Bouki V (2020) Design methodology for 360 immersive video applications: the case study of a cultural heritage virtual tour. Pers Ubiquit Comput 24 (6):843-859

7. Komppula R, Boxberg M (2002) Matkailuyrityksen tuotekehitys. Edita Oyj, Helsinki

8. Wei W (2019) Research progress on virtual reality (VR) and augmented reality (AR) in tourism and hospitality: a critical review of publications from 2000 to 2018. J Hosp Tour Technol 10(4):539-570

9. Kalevala Kartalle (2020) Experience Kalevala. https://www.kalevalakartalle.com/about-1. Accessed 29 Dec 2020

10. IGI Global (2021) What is virtual tour. https://www.igi-global.com/dictionary/virtual-tour/ 38642. Accessed 12 Jan 2021

11. Guttentag DA (2010) Virtual reality: applications and implications for tourism. Tour Manag 31(5):637-651. https://doi.org/10.1016/j.tourman.2009.07.003

12. Kim MJ, Lee CK, Jung $\mathrm{T}$ (2020) Exploring consumer behavior in virtual reality tourism using an extended stimulus-organism-response model. J Travel Res 59(1):69-89

13. Rantala K (2020) Maksullinen virtuaalimatkailu on korona-ajan uusi ilmiö - ensimmäiset japanilaisryhmät tulevat Saimaalle virtuaalisesti kesäkuussa. YLE. https://yle.fi/uutiset/311370424. Accessed 27 May 2020

14. Edvardsson B, Olsson J (1996) Key concepts for new service development. Serv Ind J 16 (2):140-164. https://doi.org/10.1080/02642069600000019

15. Komppula R (2005) Pursuing customer value in tourism - a rural tourism case study. J Hosp Tour 3(2):83-104 
16. Konu H, Tuohino A, Komppula R (2010) Lake Wellness - a practical example of a new service development (NSD) concept in tourism industries. J Vacat Mark 16(2):125-139. https://doi.org/10.1177/1356766709357489

17. Konu H (2015) Developing a forest-based wellbeing tourism product together with customers-an ethnographic approach. Tour Manag 49:1-16

18. Eriksson P, Kovalainen A (2016) Qualitative methods in business research. SAGE Publications Ltd., London

19. Jennings GR (2005) Business, social science methods used. In: Kempf-Leonard K (ed) Encyclopedia of social measurement. Elsevier, Amsterdam, pp 219-230

20. Elo S, Kyngäs H (2008) The qualitative content analysis process. J Adv Nurs 62(1):107-115

21. Hsieh H-F, Shannon SE (2005) Three approaches to qualitative content analysis. Qual Health Res 15(9):1277-1288

22. Cho Y, Wang Y, Fesenmaier DR (2002) Searching for experiences: the web-based virtual tour in tourism marketing. J Travel Tour Mark 12(4):1-17. https://doi.org/10.1300/ j073v12n04_01

Open Access This chapter is licensed under the terms of the Creative Commons Attribution 4.0 International License (http://creativecommons.org/licenses/by/4.0/), which permits use, sharing, adaptation, distribution and reproduction in any medium or format, as long as you give appropriate credit to the original author(s) and the source, provide a link to the Creative Commons license and indicate if changes were made.

The images or other third party material in this chapter are included in the chapter's Creative Commons license, unless indicated otherwise in a credit line to the material. If material is not included in the chapter's Creative Commons license and your intended use is not permitted by statutory regulation or exceeds the permitted use, you will need to obtain permission directly from the copyright holder.

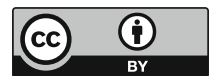

